\title{
SISTEM OTOMATISASI POMPA AIR WATER COOLING TOWER MENGGUNAKAN MIKROKONTROLER ARM STM32F4 di PT. INDOSPRING Tbk
}

\author{
Muhammad Teguh Wirawan \\ Jurusan Teknik Elektro, Fakultas Teknik, Universitas Muhammadiyah Gresik \\ hendra.umg@gmail.com \\ Jl. Sumatra No 101, Gresik 61121, Jawa Timur, Indonesia
}

\begin{abstract}
ABSTRAK
Sistem Otomatisasi Pompa Air Water Cooling Tower Menggunakan Mikrokontroler Arm Stm32f4 Di Pt.Indospring Tbk. Sebagai pusat pengontrol alat dan pemroses data. Alat ini dapat mengontrol otomatisasi motor pompa sentrifugal menggunakan sensor arus acs 712, sedangkan untuk hasil sensornya sendiri ditampilkan pada LCD (Liquid Cristal Display). Sistem kerjanya adalah jika sensor arus mendeteksi ampere berlebih pada pompa utama, maka secara otomatis pompa utama akan mati dan digantikan pompa cadangan yang telah disiapkan. Water cooling tower ini juga di lengkapi sensor suhu LM35 yang berfungsi untuk menghidupkan fan blower apabila suhu air lebih dari $40^{\circ} \mathrm{C}$. Untuk memudahkan petugas perawatan mengetahui level air kolam cooling tower maka ditambahkan sensor water level kontrol.

Berdasarkan pengujian dan pengamatan alat menggunakan tabel indikator keberhasilan telah menunjukkan bahwa Sistem Otomatisasi Pompa Air Water Cooling Tower Menggunakan Mikrokontroler Arm Stm32f4 Di PT. Indospring Tbk berjalan dengan baik.
\end{abstract}

Keyword: Sensor, motor, pompa, sirkulasi, arus

\section{PENDAHULUAN}

\subsection{Latar Belakang}

Air pendingin dan menara pendingin merupakan komponen sistem peralatan yang sangat penting dan dibutuhkan dalam setiap industri. Mengingat sering terjadi melubernya air coling tower di area produksi PT. Indospring, Tbk karena terjadi kerusakan pada motor pompa sentrifugal ataupun terjadi pemadaman listrik yang tidak diketahui oleh operator maintenance. Jika area produksi tergenang air, maka proses produksi akan dihentikan dikarenakan membahayakan mesin dan karyawan pabrik serta sangat merugikan perusahaan.

Agar masalah yang terjadi di PT. Indospring, Tbk tidak terulang lagi, maka dari pembahasan ini akan dibuat sistem otomatisasi yang dapat mengontrol motor pompa sentrifugal secara otomatis dengan motor pompa sentrifugal cadangan yang telah disiapkan bila terjadi kerusakan. Otomatisasi pompa sendiri menggunakan sensor arus, sensor arus ini juga digunakan untuk monitoring motor pompa sentrifugal. Ditambahkan juga sensor level air dan sensor suhu agar air pada kolam air cooling tower serta suhu air pada cooling tower dapat dikontrol agar proses produksi diperusahaan dapat berjalan lancar.

Dari pembahasan diatas agar masalah yang terjadi di PT. Indospring, Tbk tidak terulang lagi, maka akan dibuat "Sistem otomatisasi water cooling tower menggunakan mikrokontroler ARM STM32F4 di 
PT.Indospring Tbk”, sehingga proses

\begin{tabular}{|l|l|}
\hline \multicolumn{1}{|c|}{ Fitur } & \multicolumn{1}{c|}{ Spesifikasi } \\
\hline Ukuran & $97 \mathrm{~mm} \times 67 \mathrm{~mm}$ \\
\hline Kecepatan & $168 \mathrm{MHz}$ (maksimal) \\
\hline Flash & $1024 \mathrm{~Kb}$ \\
\hline $\begin{array}{l}\text { RAM } \\
\text { internal }\end{array}$ & $192 \mathrm{~Kb}$ \\
\hline Timer lainya & $\begin{array}{l}2 \times \text { WDG, RTC, 24-bit down } \\
\text { counter }\end{array}$ \\
\hline 12 bit ADC & 16 \\
\hline 12 ADC & 2 \\
\hline I/O & 82 \\
\hline SPI & 3 \\
\hline
\end{tabular}

produksi di PT. Indospring, Tbk dapat berjalan lancar.

\subsection{Rumusan Masalah}

Dari uraian latar belakang di atas, maka rumusan masalah yang dapat dibuat adalah bagaimana merancang dan membuat sistem otomatisasi water cooling tower menggunakan mikrokontroler ARM STM32F4.

\subsection{Tujuan Penelitian}

Adapun tujuan yang dapat diambil dari pembuatan alat ini adalah membuat sistem otomatisasi water cooling tower menggunakan mikrokontroler ARM STM32F4 di PT. Indospring, Tbk.

\section{TINJAUAN PUSTAKA}

\subsection{ARM STM32F4}

Discovery adalah salah satu jenis dari prosesor ARM 32 bit dengan tipe RISC yang sudah dilengkapi ST-LINK/V2 melalui koneksi USB.Bentuk board STM32F4 Discovery seperti Gambar 1. Di bawah ini.

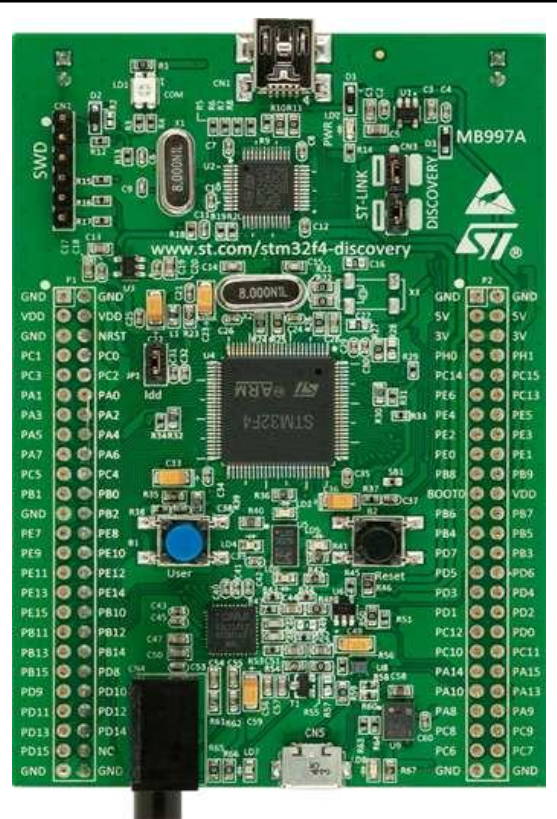

Gambar 1. STM32F4 Discovery

\subsubsection{Fitur ARM STM32F4 Discovery}

Tabel 1. Fitur ARM STM32F4 Discovery

\begin{tabular}{|l|l|}
\hline SAI & - \\
\hline PS & 2 \\
\hline PC & 3 \\
\hline USART+UART & $4+2$ \\
\hline USB OTG & 2 \\
\hline CAN 2.0B & 2 \\
\hline SDIO & 1 \\
\hline $\begin{array}{l}\text { Ethernet } \\
\text { MAC10/100 }\end{array}$ & Ya \\
\hline Tegangan kerja & $1.8-3.6 \mathrm{~V}$ \\
\hline Arus terendah & $2.5 \mathrm{Ua}$ \\
\hline Arus kerja & $238 \mathrm{uA}$ \\
\hline
\end{tabular}

\subsubsection{CooCox CoIDE}

Coocox adalah bahasa pemrograman yang tidak berbayar (freeware), yang digunakan untuk melakukan pemrograman microkontroler ARM Cortex M0, M3, dan M4 (Gambar 2.15.). CooCox IDE ini menggunakan bahasa $\mathrm{C}$ yang merupakan bahasa yang umum digunakan dalam pemrograman. Selain itu CooCox IDE menawarkan fitur-fitur menarik sebagai sebuah IDE, seperti adanya komponen (library), code completion dan lain-lain [11]. 


\subsubsection{Bahasa Pemograman STM 32F4 Berbasis Bahasa C}

Seperti yang telah dijelaskan di atas program STM 32F4 sendiri menggunakan bahasa $\mathrm{C}$. Walaupun banyak sekali terdapat bahasa pemrograman tingkat tinggi (high level language) seperti pascal, basic, cobol, dan lainnya. Walaupun demikian, sebagian besar dari para programer profesional masih tetap memilih bahasa $\mathrm{C}$ sebagai bahasa yang lebih unggul, berikut alasan-alasannya:

1. Bahasa $\mathrm{C}$ merupakan bahasayang powerful dan fleksibel yang telah terbukti dapat menyelesaikan program-program besar seperti pembuatan sistem operasi, pengola gambar (seperti pembuatan game) dan juga pembuatan kompilator bahasa pemrograman baru.

2. Bahasa $\mathrm{C}$ merupakan Bahasa yang portabel sehingga dapat dijalankan di beberapa sistem operasi yang berbeda. Sebagai contoh program yang kita tulis dalam sistem operasi windows dapat kita kompilasi didalam sistem operasi linux dengan sedikit ataupun tanpa perubahan sama sekali.

3. Bahasa $\mathrm{C}$ merupakan bahasa yang sangat popular dan banyak

digunakan oleh programer berpengalaman sehingga kemungkinan besar library pemrograman telah banyak disediakan oleh pihak luar/lain dan dapat diperoleh dengan mudah.

4. Bahasa $\mathrm{C}$ merupakan bahasa yang bersifat modular, yaitu tersusun atas rutin-rutin tertentu yang dinamakan dengan fungsi (function) dan fungsifungsi tersebut dapat digunakan kembali untuk pembuatan programprogram lainnya tanpa harus menulis ulang implementasinya.

5. Bahasa $\mathrm{C}$ merupakan bahasa tingkat menengah (middle level language) sehingga mudah untuk melakukan interface (pembuatan program antar muka) ke perangkat keras.

6. Struktur penulisan program dalam bahasa $\mathrm{C}$ harus memiliki fungsi utama, yang bernama main (). Fungsi inilah yang akan dipanggil pertama kali pada saat proses eksekusi program. Artinya apabila kita mempunyai fungsi lain selain fungsi utama, maka fungsi lain tersebut baru akan dipanggil pada saat digunakan.

\subsection{Sensor arus ACS 712}

ACS 712 adalah Hall effect current sensor. Hall effect callegro 712 merupakan sensor yang presisi sebagai sensor arus AC atau DC dalam pembacaan arus didalam dunia industri, otomotif, komersil, dan sistem komunikasi. Pada umumnya aplikasi sensor ini biasanya digunakan untuk mengontrol motor deteksi beban listrik, switched- mode power supplies dan proteksi beban lebih [1].

Bentuk fisik dari sensor arus ACS 712 dapat dilihat pada Gambar 2 di bawah ini:

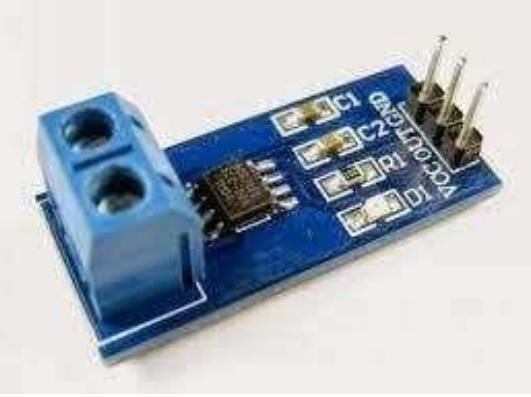

Gambar 2. Sensor arus ACS 712

\subsubsection{Fitur ACS 712}

Fitur yang dimiliki ACS 712 sebagai berikut:

1. Rise time output $=5$ us.

2. Bandwith sampai dengan $80 \mathrm{KHz}$.

3. Total kesalahan output $1,5 \%$ pada suhu kerja $\mathrm{TA}=25^{\circ} \mathrm{C}$.

4. Tahanan konduktor internal 1.2 $\mathrm{M} \Omega$. 
Volume 15 Nomor 2 (2020) 23-35

E-Link P-ISSN 1858-2109 E-ISSN 2656-5676

Jurnal Teknik Elektro dan Informatika

5. Tegangan isolasi minimum $2.1 \mathrm{kV}$ RMS antara pin 1-4 dan pin 5-8.

6. Sensitivitas output $185 \mathrm{mV} / \mathrm{A}$.

7. Mampu mengukur arus $\mathrm{AC}$ atau DC hingga 5A.

8. Tegangan output proporsional terhadap input arus AC atau DC.

9. Tegangan kerja 5V DC.

Rumus tegangan pada pin out $=2,5 \pm$ $(0,85 \times$ I) Volt, dimana $\mathrm{I}=$ arus yang terdeteksi dalam satuan Ampere.

\subsection{Pompa Air Sentrifugal}

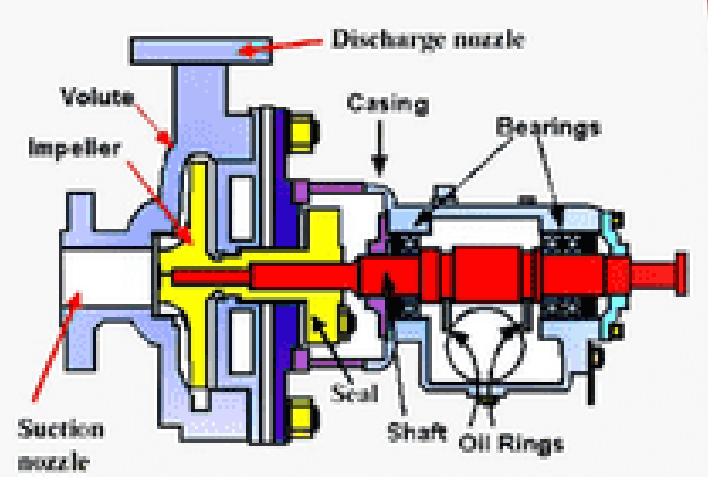

Gambar 3. Pompa Air Sentrifugal

Pompa Sentrifugal atau centrifugal pumps adalah pompa yang mempunyai elemen utama yakni berupa motor penggerak dengan impeller yang berbutar dengan kecepatan tinggi seperti pada Gambar 3. Prinsip kerjanya yakni mengubah energi mekanis alat penggerak menjadi energi kinetis fluida (kecepatan) kemudian fluida di arahkan ke saluran buang dengan memakai tekanan (energi kinetis sebagian fluida diubah menjadi energi tekanan) dengan menggunakan impeller yang berputar di dalam casing. Casing tersebut dihubungkan dengan saluran hisap (suction) dan saluran tekan (discharge), untuk menjaga agar di dalam casing selalu terisi dengan cairan sehingga saluran hisap harus dilengkapi dengan katup kaki (foot valve) [5].

\subsection{Liquid Crystal Display}

LCD adalah suatu jenis tampilan yang menggunakan kristal cair sebagai penampil utama dengan menggunakan sistem dot matrik pada pengoperasiannya [5]. LCD sudah digunakan diberbagai bidang misalnya dalam alat alat elektronik seperti televisi, kalkulator,

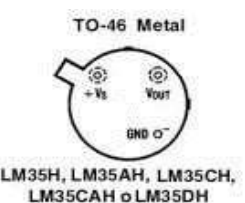
LM35CAHOLM L 35 DH

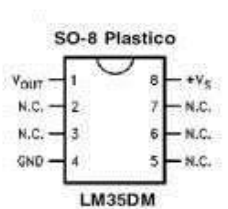

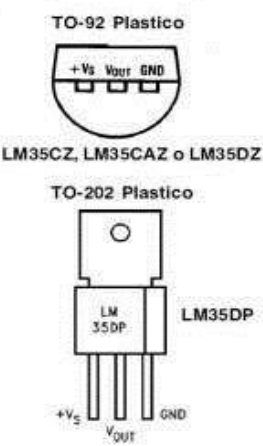
multitester digital, jam digital ataupun layar komputer. Keunggulan LCD adalah mikrokontroler yang ingin menampilkan suatu pesan tidak terbebani oleh masalah tampilan karena didalam LCD telah terdapat controller yang akan menampilkan karakter yang diinginkan. LCD dapat dengn mudah dihubungkan dengan mikrokontroller AVR At mega 32. Pada tugas akhir ini LCD yang digunakan adalah LCD 2x16, lebar display 2 baris 16 kolom. Bentuk LCD 2x16 dapat dilihat pada Gambar 4.

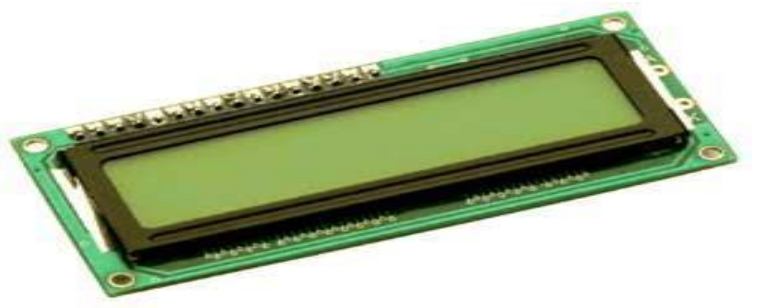

Gambar 4. Liquid Crystal Display

\subsection{Sensor Suhu IC LM35}

Sensor suhu IC LM 35 merupkan chip IC produksi Natioanal Semiconductor yang 
berfungsi untuk mengetahui temperature suatu objek atau ruangan dalam bentuk besaran elektrik, atau dapat juga di definisikan sebagai komponen elektronika yang berfungsi untuk mengubah perubahan temperature yang diterima dalam perubahan besaran elektrik. Sensor suhu IC LM35 dapat mengubah perubahan temperature menjadi perubahan tegangan pada bagian out putnya. Sensor suhu IC LM35 membutuhkan sumber tegangan $\mathrm{DC}+5$ volt dan konsumsi arus DC sebesar $60 \mu \mathrm{A}$ dalam beroperasi. Bentuk fisik sensor suhu LM 35 merupakan chip IC dengan kemasan yang berfariasi, pada umumnya kemasan sensor suhu LM35 adalah kemasan TO-92 seperti terlihat pada gambar dibawah.

\section{Gambar 5. Sensor LM 35}

Dari Gambar 5. dapat diketahui bahwa sensor suhu IC LM35 pada dasarnya memiliki 3 pin yang berfungsi sebagai sumber supply tegangan DC +5 volt, sebagai pin output hasil penginderaan dalam bentuk perubahan tegangan DC pada Vout dan pin untuk Ground [7].

Karakteristik Sensor suhu IC LM35 adalah:

- Memiliki sensitivitas suhu, dengan faktor skala linier antara tegangan dan suhu $10 \mathrm{mVolt} /{ }^{\circ} \mathrm{C}$, sehingga dapat dikalibrasi langsung dalam celcius.

- Memiliki ketepatan atau akurasi kalibrasi yaitu $0,5^{\circ} \mathrm{C}$ pada suhu $25^{\circ} \mathrm{C}$ seperti terlihat pada gambar 2.2 .

- Memiliki jangkauan maksimal operasi suhu antara $-55^{\circ} \mathrm{C}$ sampai $+150^{\circ} \mathrm{C}$.

- Bekerja pada tegangan 4 sampai 30 volt.

- Memiliki arus rendah yaitu kurang dari $60 \mu \mathrm{A}$.
- Memiliki pemanasan sendiri yang rendah (low-heating) yaitu kurang dari $0,1^{\circ} \mathrm{C}$ pada udara diam.

- Memiliki impedansi keluaran yang rendah yaitu $0,1 \mathrm{~W}$ untuk beban 1 $\mathrm{mA}$.

- Memiliki ketidak linieran hanya sekitar $\pm 1 / 4{ }^{\circ} \mathrm{C}$.

\subsection{Water Level Control}

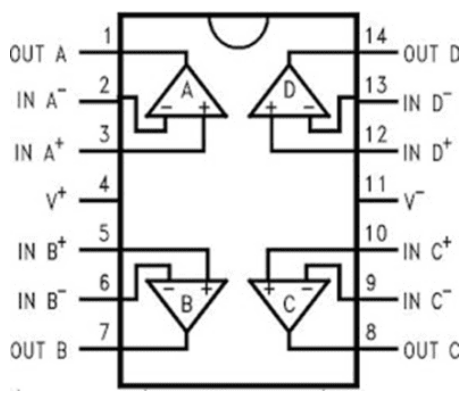

Gambar 6. Datasheet IC Komparator LM324

Prinsip kerja rangkaian kerja rangkaian komparator menggunakan IC LM324 yang di dalamnya berisi rangkaian Op Amp, seperti pada Gambar 6, rangkaian ini digunakan untuk membndingkan input sensor. Untuk mengatur tegangan pada pembanding, disambungkan Variabel Resistor (VR) diantara kedua Op Amp IC LM324.

Untuk datasheet LM324 adalah sebagai berikut: IC LM324 merupakan IC operational Amplifier, IC ini mempunyai 4 buah op-amp yang berfungsi sebagai komparator. IC ini mempunyai tegangan kerja antara $+5 \mathrm{~V}$ sampai $+15 \mathrm{~V}$ untuk $+\mathrm{VCC}$. Adapun definisi dari masing-masing pin IC LM324. Dalam gambar di atas Pin 1,7,8,14 adalah sinyal output Pin 3,5,10,12 disebut pin Non- inverting input karena semua sinyal input yang berada di pin ini akan mempunyai output yang sama dengan input (tidak berkebalikan). Pin 2, 6, 9, 13 disebut inverting input karena semua sinyal input yang berada di pin ini tidak sama dengan output (berkebalikan). Pin $4(+\mathrm{Vcc})$ pin ini dapat beroprasi antara $+5 \mathrm{v}$ sampai $+15 \mathrm{v}$, pin 
11(-Vcc) pin ini dapat beroprasi pada tegangan antar $-5 \mathrm{v}$ sampai $-15 \mathrm{v}$

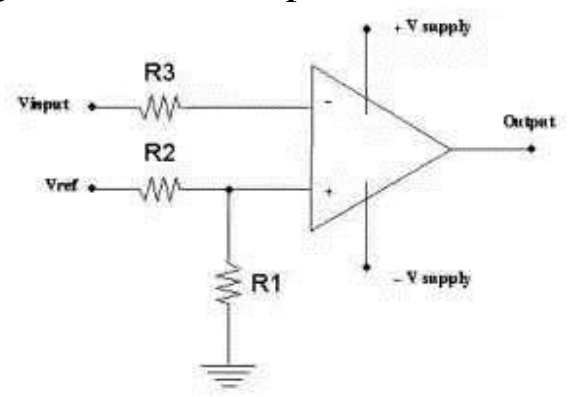

Gambar 7. Rangkaian Circuit Sensor Water Level Control

Sensor dibuat menggunakan batangan Logam anti-karat logam as atau stal berdiameter 2-3 $\mathrm{mm}$ dapat diperoleh di tokotoko logam. Panjang masing-masing batangan sensor disesuaikan dengan kedalaman tandon.

Rangkaian circuit sensor water menggunakan arus yang sangat kecil sehingga meminimalisasi proses elektrolisasi sehingga sensor tidak cepat berkerak. Untuk perawatan, batangan sensor dibersihkan dengan cara dicuci untuk menghilangkan gejala-gejala pengerakan. atau dapat juga dengan menggunakan amplas super halus.

Rangkaian di atas dapat diaplikasikan pada sistem atau sebagai pendukung sistem sebagai berikut:

- Kontrol level air tandon pada rumah tangga

- Kontrol level air tandon boiler

- Kontrol level kolam air minum pada rumah walet

- Kontrol level kolam air pada humidifier penetas telur

- Alarm peringatan tandon kosong atau tandon penuh

- Dan lain-lain

\section{METODE PENELITIAN}

\subsection{Studi Literatur}

Metode penelitian dimulai dengan studi literatur, yaitu mencari informasi melalui buku-buku, internet, jurnal, dan data sheet yang berhubungan dengan elemenelemen yang dipakai dalam penelitian ini, adapun literatur-literatur yang dipelajari antara lain sebagai berikut:

1. Mikrokontroler

STM32F407

Discovery

2. Motor listrik

3. Pompa air sentrifugal

4. Sensor suhu IC LM35

5. Sensor arus ACS712

6. Liquid Crystal Display (LCD)

7. Sensor Water Level

8. Pemrogram CooCox CoIDE

\subsection{Perancangan Hardware dan Pembuatan Software Alat}

Sistem otomatisasi pompa air water cooling tower menggunakan mikrokontroler ARM STM32F4 di PT. Indospring, Tbk, secara garis besar terdiri dari perangkat keras (hardware) dan perangkat lunak (software). Perangkat keras terdiri dari rangkaian mikrokontroler STM32F407 discovery, sensor arus ACS 712 sebagai pembacaan arus pada motor pompa sentrifugal, sensor suhu IC LM35, LCD, water level control, dan motor DC. Sedangkan perangkat lunak adalah program yang ditulis dan di-download pada chip STM32F407 menggunakan program CooCox CoIDE dengan media utama komputer.

Sistem otomatisasi pompa air water cooling tower menggunakan mikrokontroler ARM STM32F4 dirancang dengan konstruksi secara garis besar terdiri dari dari dua perangkat utama:

1. Perangkat elektronik / lunak (software), yaitu alir diagram program yang dibuat untuk menjalankan sistem mekanik.

2. Perangkat keras (hardware), yaitu berupa rangkaian sistem mekanik dan rangkaian pengendali.

\subsubsection{Perancangan Hardware}

Dalam perancangan dan pembuatan alat otomatisasi pompa air cooling tower ini menggunakan beberapa perangkat elektronik, 
Volume 15 Nomor 2 (2020) 23-35

E-Link P-ISSN 1858-2109 E-ISSN 2656-5676

Jurnal Teknik Elektro dan Informatika

diantaranya: power supply, STM32F407, sensor arus, sensor suhu, water level control, LCD dan motor DC.

Gambaran secara umum cara kerja alat otomatisasi water cooling tower ini adalah otomatisasi kontrol pada motor pompa sentrifugal, jika motor pompa mengalami ampere berlebih maka motor pompa tersebut akan mati dan digantikan dengan motor pompa cadangan yang telah disiapkan secara otomatis. Water cooling tower juga diberi sensor level air dan sensor suhu air untuk mengontrol kerja tidaknya kipas pendingin. Gambar 8, menunjukkan diagram blok sistem secara umum atau keseluruhan dari otomatisasi water cooling tower:

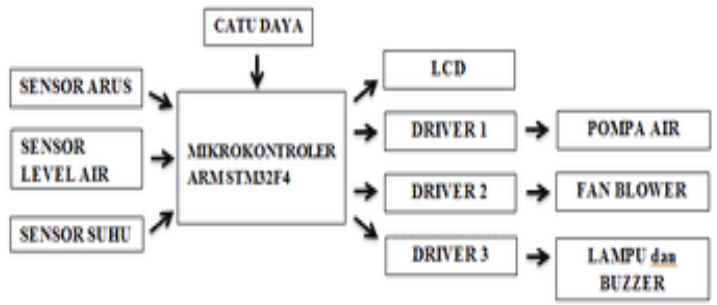

Gambar 8. Diagram Blok Sistem Mikrokontrololer

Berdasarkan Gambar 8, bagian-bagian yang dibutuhkan untuk membuat alat ini adalah sebagai berikut:

1. Catu daya 5-12 VDC digunakan sebagai sumber bagi mikrokontroller, sensor-sensor serta IC pendukung lainnya. Seperti yang dijelaskan pada Gambar 9, di bawah ini.

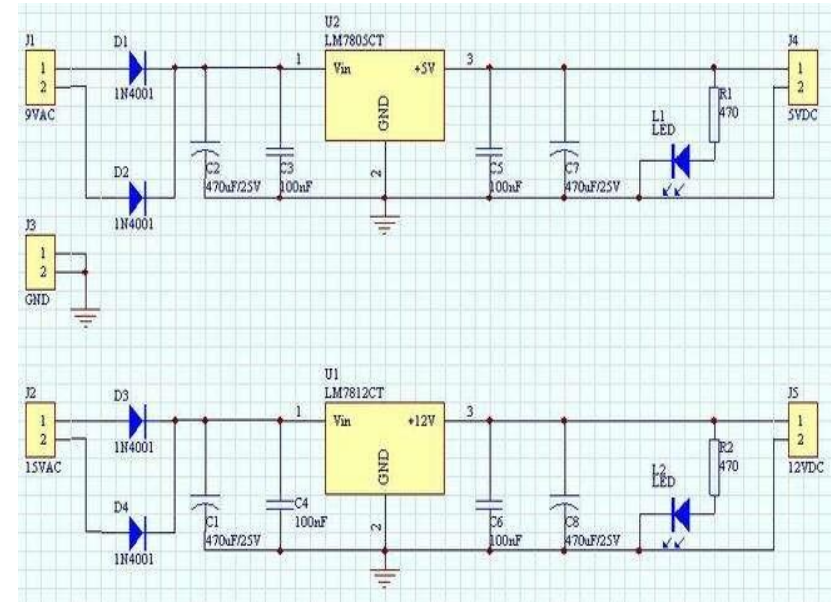

Gambar 9. Rangakaian Catu Daya
- Trafo 2 Amp CT-18V Universal dipilih karena dilihat dari beban yang dibutuhkan:

- Sebuah board ARM STM32F4

- 5 buah relay 5 vdc, 70x $5=$ $350 \mathrm{~mA}$

- 4 motor pompa $12 \mathrm{vdc}, 20 \mathrm{x} 4=$ $800 \mathrm{~mA}$

- 1 fan blower $12 \mathrm{vdc}, 100 \mathrm{~mA}$

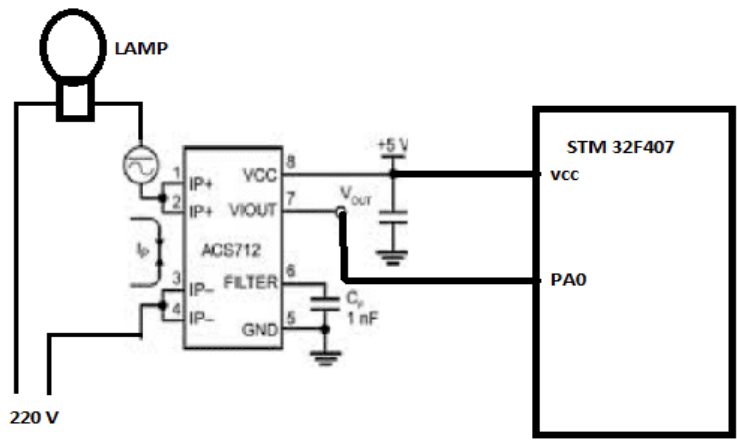

- IC LM7805 digunakan untuk mensuplay board ARM STM32F4, sensor, dan 5 buah relay $5 \mathrm{vdc}$.

- IC LM 7812 digunakan untuk mensuplay 4 motor pompa 12 vdc dan 1 fan blower 12 vdc.

2. 4 buah pompa air sentrifugal, sebuah fan blower, dan lain-lain.

3. Rangkaian pengendali untuk mengatur semua proses kerja alat menggunakan Mikrokontroller STM32f4 discovery ditambah sebuah LCD 16X2, rangkaian push button, dan driver relay output. $\mathrm{PB} 1=\mathrm{PC} 0$, $\mathrm{PB} 2=\mathrm{PC} 1, \quad \mathrm{~PB} 3=\mathrm{PC} 2, \quad \mathrm{~PB} 4=\mathrm{PC} 3$, $\mathrm{PB} 5=\mathrm{PC} 4$. 
Volume 15 Nomor 2 (2020) 23-35

E-Link P-ISSN 1858-2109 E-ISSN 2656-5676

Jurnal Teknik Elektro dan Informatika

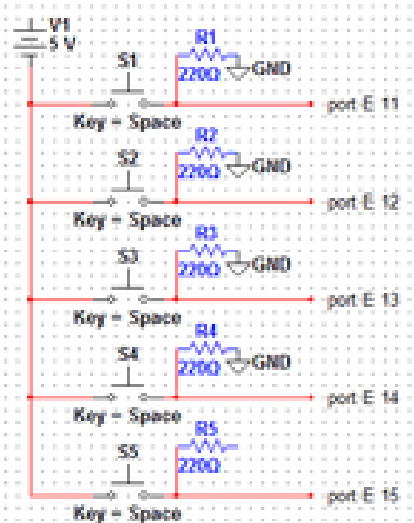

Gambar 10. Rangkaian Pengendali Push Button

Dari Gambar 10 di atas, setiap line yang langsung ke mikrokontroler dihubungkan keground melalui resistor 220 ohm agar saat phus button ditekan power mikro tidak konslet. Sehingga saat tidak ditekan mikrokontroler membaca nilai 0 dan saat ditekan mikrokontroler membaca nilai 1 .

4. Sensor arus ACS712 digunakan sebagai otomatis pompa air Vcc=5v, Gnd, Out=PA0. Sedangkan untuk cara pemakaian sensor dijelaskan pada Gambar 11

Gambar 11. Rangkaian Pemasangan Pin Sensor ACS712

5. Sensor suhu IC LM35 digunakan untuk otomatisasi fan blower $\mathrm{Vcc}=3 \mathrm{v}$, Gnd, Out=PA3 . Cara pengaplikasian sensor dijelaskan Gambar 12.

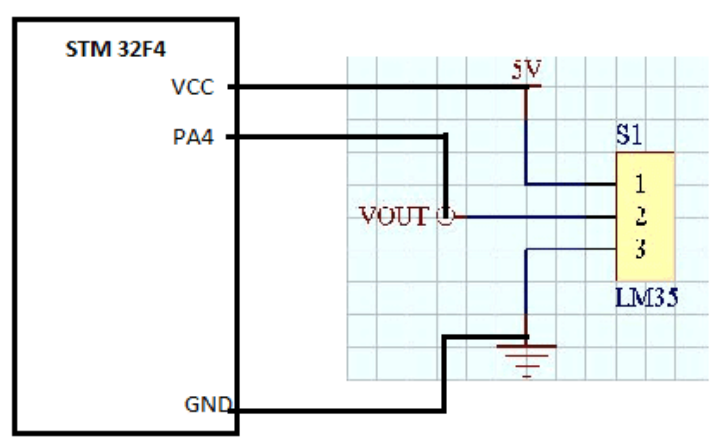

Gambar 12. Rangkaian pemasangan sensor LM35

6. Water Level Control LM324 digunakan untuk level air. LM324 adalah sebuah ic op-amp com $=$ vcc, output $=$ PA5, PA6, PA7 dan untuk penjelasannya dijelaskan pada Gambar 13.
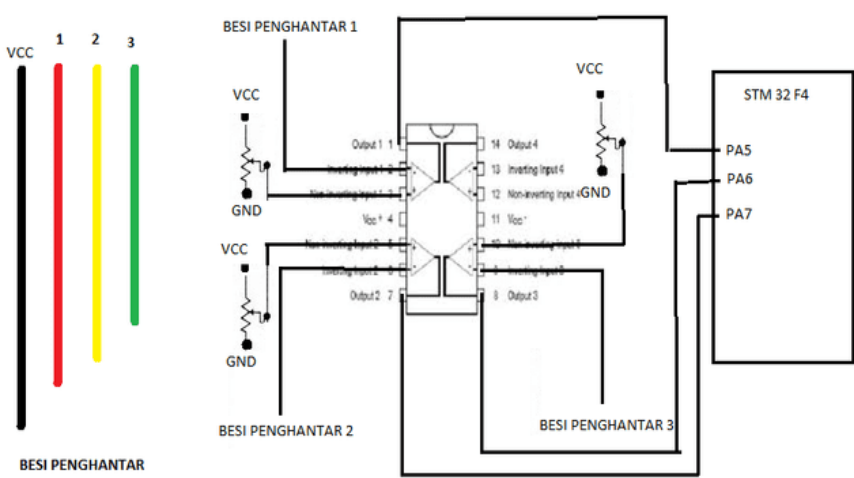

Gambar 13. Rangkaian Pemasangan Sensor Water Level

Pada dasarnya kumparator LM324 adalah membandingkan tegangan input dari sensor dan tegangan input dari variabel resistor yang kemudian di perbesar tegangannya berkali-lipat dan dikeluarkan melalui output. Maka digunakan variable resistor $20 \mathrm{k} \mathrm{ohm}$, sedangakan konduktornya menggunakan batang tembaga.

7. Rangkaian Liquid Crystal Display (LCD) untuk monitoring arus motor. Sistematik rangkaian LCD 16X2 seperti pada Gambar 14 menggunakan variable resistor $20 \mathrm{k}$ ohm untuk pengaturan kontrasnya. 


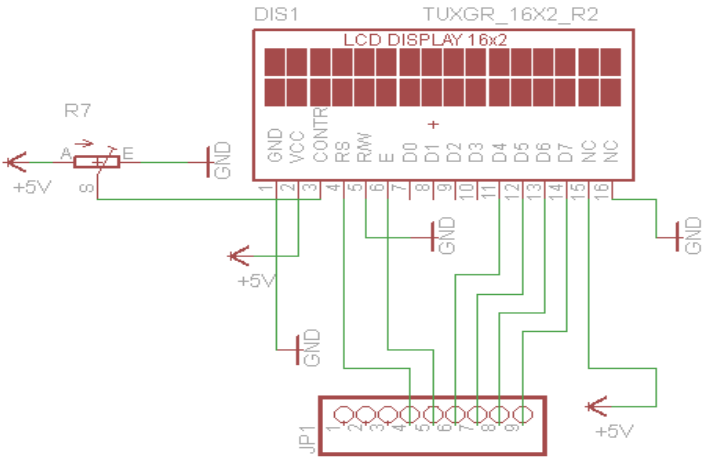

Gambar 14. Rangkaian LCD

8. Rangkaian output sistem adalah display LCD, relay, motor pompa, fan blower dan indikator tambahan lainnya. Rangkaian kontrol relay dijelaskan pada Gambar 15.

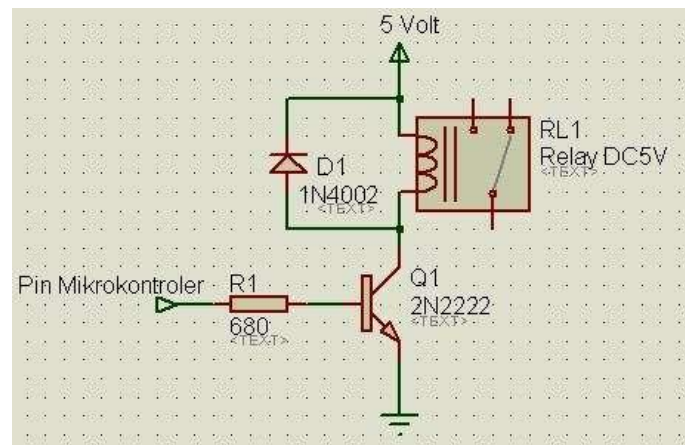

Gambar 15. Rangkaian Kontrol Relay 5v

Transistor yang digunakan 2n222 dikarenakan mampu menghantarkan arus sebesar $600 \mathrm{~mA}$, untuk relay digunakan relay huike $5 \mathrm{vdc}$ karena mudah dicari di pasaran.

\subsubsection{Pembuatan Software}

Pada pembuatan alat sistem otomatisasi pompa air water cooling tower, kode program yang telah ditulis akan didownload keprosesor STM32F4 Discovery menggunakan program CoIDE. CoIDE adalah sebuah program yang telah dikembangkan secara umum untuk memberikan akses kemudahan dalam pemrograman prosesor ARM. Program dibuat dan disesuaikan sehingga sistem berjalan dengan baik.

Secara umum flowchart utama program sistem otomatisasi pompa air water cooling tower menggunakan mikrokontroler ARM STM32F407.

\section{HASIL DAN PEMBAHASAN \\ 4.1 Pengujian Sistem Minimum ARM STM32F407 Discovery}

Pengujian system yang telah dilakukan ini merupakan pengujian terhadap perangkat keras serta perangkat lunak dari system secara keseluruhan yang telah selesai dibuat untuk mengetahui komponenkomponen dari sistem tersebut apakah sistem tersebut berjalan dengan baik. Pengujian minimum system bertujuan untuk mengetahui apakah minimum system dapat melakukan proses connect dan download program ke microcontroller dengan baik.

Peralatan-peralatan yang dibutuhkan untuk pengujian pin-pin digital antara lain:

1. PC

2. Board sistem minimum ARM STM32F4 Discovery

3. Software CooCox CoIDE

4. LED

5. Resistor $220 \mathrm{ohm}$

Langkah-langkah cara pengujian pin-pin digital board sistem minimum ARM STM32F4 Discovery yaitu:

1. Merangkai LED pada board sistem minimum ARM STM32F4 Discovery.

2. Memberikan program pada board sistem minimum ARM STM32F4 Discovery.

Dengan meng-upload program maka LED akan menyala selama satu detik dan kemudian padam selama satu detik demikian seterusya. Maka pin-pin digital rangkaian board sistem minimum ARM STM32F4 dalam keadaan baik.

Setelah pengujian pin-pin digital selesai, selanjutnya dilakukan pengujian pada pin-pin analog pada board sistem minimum ARM STM32F4 Discovery. Peralatan-peralatan yang dibutuhkan antara lain:

1. PC.

2. Board sistem minimum ARM STM32F4 Discovery. 
3. Software CooCox CoIDE.

4. LED.

5. Push button.

6. Resistor 220 ohm dan $10 \mathrm{k}$ ohm.

Langkah-langkah cara pengujian pin-pin digital board sistem minimum ARM STM32F4 Discovery yaitu:

1. Merangkai LED dan push button pada board sistem minimum ARM STM32F4 Discovery.

2. Memberikan program pada board sistem minimum ARM STM32F4 Discovery.

Dengan meng-upload program ke board sistem minimum, maka LED akan menyala jika push button ditekan dan LED akan mati jika push button dilepas. Maka pinpin analog rangkaian board sistem minimum ARM STM32F4 Discovery dalam keadaan baik.

\section{2 . Pengujian Sensor Level Air}

Pengujian sensor level air ini dilakukan dengan mencelubkan sensor ke permukaan air sesuai batas yang ditentukan secara berulang-ulang. Setelah melakukan pengujian sensor level air, hasil pengujian dicatat pada Tabel 2.

Tabel 2. Hasil Pengujian Sensor Level Air

\begin{tabular}{|c|c|c|c|c|c|c|c|c|}
\hline \multirow[b]{2}{*}{ No. } & \multirow{2}{*}{$\begin{array}{c}\text { Level } \\
\text { Air } \\
\text { Kolam } \\
\left(100 \mathrm{~m}^{3}\right)\end{array}$} & \multicolumn{5}{|c|}{ Pengujian niai ADC } & \multirow[b]{2}{*}{ Output } & \multirow{2}{*}{$\begin{array}{c}\text { Kesalah } \\
\text { an }(\%)\end{array}$} \\
\hline & & Acuan & 1 & 2 & 3 & 4 & & \\
\hline 1 & $<50 \mathrm{~m}^{3}$ & 1000 & $\begin{array}{l}10 \\
10\end{array}$ & $\begin{array}{l}10 \\
05\end{array}$ & $\begin{array}{l}10 \\
12\end{array}$ & $\begin{array}{l}10 \\
00\end{array}$ & $\begin{array}{c}\text { Lampu } \\
\text { Kuning } \\
\text { on }\end{array}$ & $2.70 \%$ \\
\hline 2 & $\begin{array}{c}50-70 \\
\mathrm{~m}^{3}\end{array}$ & 1455 & $\begin{array}{l}14 \\
50\end{array}$ & $\begin{array}{l}14 \\
20\end{array}$ & $\begin{array}{l}14 \\
15\end{array}$ & $\begin{array}{l}14 \\
20\end{array}$ & $\begin{array}{c}\text { Lampu } \\
\text { Hijau } \\
\text { on }\end{array}$ & $\begin{array}{c}11.50 \\
\%\end{array}$ \\
\hline 3 & $\begin{array}{c}70-90 \\
\mathrm{~m}^{3}\end{array}$ & 1500 & $\begin{array}{l}15 \\
00\end{array}$ & $\begin{array}{l}14 \\
80\end{array}$ & $\begin{array}{l}15 \\
00\end{array}$ & $\begin{array}{l}14 \\
90\end{array}$ & $\begin{array}{c}\text { Lampu } \\
\text { Kuning } \\
\text { on }\end{array}$ & $3.00 \%$ \\
\hline 4 & $<90 \mathrm{~m}^{3}$ & 1430 & $\begin{array}{l}14 \\
30\end{array}$ & $\begin{array}{l}14 \\
20\end{array}$ & $\begin{array}{l}14 \\
10\end{array}$ & $\begin{array}{l}14 \\
30\end{array}$ & $\begin{array}{c}\text { Lampu } \\
\text { Merah } \\
\text { on }\end{array}$ & $3.00 \%$ \\
\hline
\end{tabular}

Dari data Tabel 4, pengujian dengan cara mencoba sensor level air secara berulangulang sebanyak 4x. Dari 4 data percobaan diatas selisih adc sangat sedikit sehingga dapat disimpulkan bahwa sensor level air bekerja dengan baik.

\subsection{Pengujian Sensor Arus ACS 712 Terhadap Ampere Motor Pompa Air Sentrifugal}

Hall Effect Sensor akan menghasilkan sebuah tegangan yang proporsional dengan kekuatan medan magnet yang diterima oleh sensor tersebut. Pendeteksian perubahan kekuatan medan magnet cukup mudah dan tidak memerlukan apapun selain sebuah induktor yang berfungsi sebagai sensornya. Kelemahan dari detektor dengan menggunakan induktor adalah kekuatan medan magnet yang statis (kekuatan medan magnet nya tidak berubah) tidak dapat dideteksi. Sensor ini terdiri dari sebuah lapisan silikon yang berfungsi untuk mengalirkan arus listrik. Berikut langkah langkah untuk melakukan pengujian ini adalah sebagai berikut:

1. Hubungkan ARM STM32F4 Discovery dengan port USB (Universal Serial Bus) pada komputer. Dengan cara ini modul akan aktif, karena secara langsung mendapat suplay daya dari port USB (Universal Serial Bus).

2. Buka software CooCox CoIDE dimulai dengan membuat lembar project baru, dengan cara menekan tombol Project kemudian New Project. Akan tampil window new project

3. Kemudian isi project name (nama projek) dan project path (tempat penyimpanan projek) sesuai dengan

4. sensor ACS712 pada pin VCC ke 5v,

5. Analog PA0.

6. Masukkan arus yang bersumber dari adapter, sedangkan pada ACS712 di masukan beban dari arus DC menggunakan beban motor DC (Motor pompa air sentrifugal). 
Volume 15 Nomor 2 (2020) 23-35

E-Link P-ISSN 1858-2109 E-ISSN 2656-5676

Jurnal Teknik Elektro dan Informatika

7. Motor pompa sentrifugal berjalan dengan beban air, kemudian diamati pembacaan arus pada LCD. Ketika ampere melebihi 0,25 A maka motor pompa utama akan mati secara otomatis, kemudian digantikan dengan pompa cadangan agar sirkulasi water cooling tower dapat terjaga dan proses produksi dapat berjalan lancar.

Setelah dilakukan pengujian sensor ACS712 maka hasil yang didapatkan sesuai dengan Tabel 3 di bawah ini.

Tabel 3. Hasil Sensor Arus ACS 712 pada Motor Pompa Air Sentrifuga

\begin{tabular}{|c|c|c|l|l|l|l|}
\hline No & $\begin{array}{c}\text { Motor } \\
\text { Pompa } \\
\text { Air } \\
\text { Sentrifu } \\
\text { gal }\end{array}$ & $\begin{array}{c}\text { Pengujian } \\
\text { Kosong } \\
\text { (Air) }\end{array}$ & $\begin{array}{c}\text { Pengujian } \\
\text { Beban } \\
\text { (Air) }\end{array}$ & $\begin{array}{c}\text { Pengujian } \\
\text { Motor } \\
\text { Over } \\
\text { Load }\end{array}$ & $\begin{array}{c}\text { Menggu } \\
\text { nakan } \\
\text { Avoeter } \\
\text { Sanwa }\end{array}$ & $\begin{array}{c}\text { Kesalahan } \\
(\%)\end{array}$ \\
\hline 1. & P1 & $0.030 \mathrm{~A}$ & $0.21 \mathrm{~A}$ & $0.47 \mathrm{~A}$ & $0.39 \mathrm{~A}$ & $20.5 \%$ \\
\hline 2. & P2 & $0.034 \mathrm{~A}$ & $0.27 \mathrm{~A}$ & $0.43 \mathrm{~A}$ & $0.40 \mathrm{~A}$ & $7.5 \%$ \\
\hline 3. & P3 & $0.035 \mathrm{~A}$ & $0.22 \mathrm{~A}$ & $0.41 \mathrm{~A}$ & $0.43 \mathrm{~A}$ & $4.6 \%$ \\
\hline 4. & P4 & $0,032 \mathrm{~A}$ & $0.25 \mathrm{~A}$ & $0.45 \mathrm{~A}$ & $0.41 \mathrm{~A}$ & $9.7 \%$ \\
\hline \multicolumn{7}{|l}{ Total Presetase Kesalahan } \\
\hline
\end{tabular}

\section{Keterangan :}

$\mathrm{P} 1=$ Pompa utama $1 \quad \mathrm{P} 3=$ Pompa utama 2

$\mathrm{P} 2=$ Pompa cadangan $1 \quad \mathrm{P} 4=$ Pompa cadangan 2

Dari data Tabel 3, pengujian sensor arus ACS712 dilakukan pada masing-masing pompa dan dengan beban yang sama, penunjukan sensor ACS712 relative tidak stabil. Sehingga dapat disimpukan bahwa sensor ini kurang akurat dikarenakan beban sensor yang sangat kecil.

\subsection{Pengujian LCD 16x2}

Pengujian LCD 16x2 menggunakan sistem minimum ARM STM32F4 Discovery sebagai alat untuk memerintahkan beberapa karakter. LCD ini nantinya akan menampilkan arus, suhu dan level. Setelah LCD 16x2 dirangkai dengan sistem minimum ARM STM32F4 Discovery selanjutnya upload program menggunakan CooCox CoIDE. Jika sukses maka LCD 16x2 siap untuk digunakan. hasil yang didapatkan sesuai dengan Tabel 4.

Tabel 4. Hasil Pengujian Rangkaian LCD

\begin{tabular}{|c|c|}
\hline Masukan & Keluaran LCD \\
\hline M. Teguh Wirawan & M. Teguh Wirawan \\
\hline 12.632 .006 & 12.632 .006 \\
\hline TEKNIK ELEKTRO & TEKNIK ELEKTRO \\
\hline UNMUH GRESIK & UNMUH GRESIK \\
\hline
\end{tabular}

\subsection{Pengujian Sensor Suhu LM35}

Pengujian pada sensor suhu dilakukan dengan mengukur tegangan output dari sensor dan meletakan sumber panas pada sensor suhu LM35 untuk mengetahui suhu yang akan ditampilkan pada LCD, Langkahlangkah pengujian:

1. Sensor suhu LM35 dirangkai sesuai rangkaian.

2. Sensor suhu LM35 dicelupkan ke air hangat.

3. Vec sensor dihubungkan ke Vcc mikro, Gnd sensor dihubungkan ke Gnd mikro, V out sensor di masukkan ke pin adc mikro, hasil pembacaan sensor ditampilkan di LCD.

4. Tegangan keluaran sensor diamati sesuai perubahan suhu.

5. Tegangan output LM35 diukur pada suhu yang berbeda-beda seperti Tabel 5 di bawah ini.

Dari data Tabel 5 analisa presentase kesalahan bisa diperoleh dengan rumus di bawah ini:

$\%$ Error $=\left|\frac{\text { nilai aktual-nilai acuan }}{\text { nilai acuan }}\right| \times 100 \%$.

Contoh perhitungan persentase kesalahan: 
Volume 15 Nomor 2 (2020) 23-35

E-Link P-ISSN 1858-2109 E-ISSN 2656-5676 Jurnal Teknik Elektro dan Informatika

$$
\begin{gathered}
\% \text { Error }=\left|\frac{37^{\circ} \mathrm{C}-35^{\circ} \mathrm{C}}{35^{\circ} \mathrm{C}}\right| \times 100 \% \\
\text { Error }=5,7 \%
\end{gathered}
$$

Dari data Tabel 5, di atas pengujian diketahui tegangan keluaran sensor LM35 naik sebesar $0.5 \mathrm{~V}$ setiap $5^{\circ} \mathrm{C}$ atau $0.1 \mathrm{mV} /{ }^{\circ} \mathrm{C}$. Sehingga dapat disimpukan bahwa sensor ini masih bekerja dengan baik dan bekerja dengan baik.

Tabel 5. Hasil Pengukuran Tegangan Output

$$
\text { LM35 }
$$

\begin{tabular}{|c|c|c|c|}
\hline $\begin{array}{c}\text { Suhu } \\
\text { Thermometer }\end{array}$ & $\begin{array}{c}\text { Tegangan } \\
\text { Output } \\
\text { LM35 }\end{array}$ & $\begin{array}{c}\text { Percobaan } \\
\text { Sensor Suhu } \\
\text { LM35 }\end{array}$ & $\begin{array}{c}\text { Kesalahan } \\
(\%)\end{array}$ \\
\hline $30^{\circ} \mathrm{C}$ & $321 \mathrm{mV}$ & $31^{\circ} \mathrm{C}$ & $3.3 \%$ \\
\hline $35^{\circ} \mathrm{C}$ & $376 \mathrm{mV}$ & $37^{\circ} \mathrm{C}$ & $5.7 \%$ \\
\hline $40^{\circ} \mathrm{C}$ & $433 \mathrm{mV}$ & $39^{\circ} \mathrm{C}$ & $2.5 \%$ \\
\hline $40^{\circ} \mathrm{C}$ & $480 \mathrm{mV}$ & $44^{\circ} \mathrm{C}$ & $2.2 \%$ \\
\hline $50^{\circ} \mathrm{C}$ & $534 \mathrm{mV}$ & $48^{\circ} \mathrm{C}$ & $4 \%$ \\
\hline \multicolumn{2}{|c|}{ Total Presentase Kesalahan } & $3.54 \%$ \\
\hline
\end{tabular}

\section{PENUTUP}

\subsection{Kesimpulan}

Berdasarkan hasil penelitian dan pembahasan tentang alat sistem otomatisasi pompa air water cooling tower menggunakan mikrokontroler ARM STM32F4 di PT. Indospring Tbk, maka disimpulkan bahwa:

1. Alat secara umum telah mampu bekerja sesuai dengan perancangan

2. Pada saat pengujian alat sudah menunjukkan sesuai dengan nilai tertentu.

3. Sensor suhu menunjukkan persentase kesalahan pembacaan sensor sebesar 3,54\% berarti sensor LM35 termasuk sensor yg akurat.

4. Sensor level air yang digunakan akurat dengan persentase kesalahan $5,05 \%$.

5. Sensor arus ACS712 tergolong sensor yang kurang akurat dilihat dari hasil pengujian sensor dengan persentase kesalahan alat $10,5 \%$.

\subsection{Saran}

penulis memberikan saran yang sangat bermafaat dan dapat membantu mengembangkan alat yang sudah ada untuk masa yang akan datang, yaitu:

1. Alat ini dapat dikembangkan lebih lanjut dengan menambahkan sistem otomatisasi buka tutup ball valve pipa output pompa sentrifugal agar flow air dapat dikontrol.

2. Menambahkan sistem kontrol PH air pada cooling tower agar kandungan air pada cooling tower dapat dikontrol sehingga tidak merusak komponen cooling tower atau mengurangi fungsi pendingin itu sendiri.

\section{DAFTAR PUSTAKA}

[1] A. R. Harfit, "Perawatan Berkala Sistem Pendingin Udara," Universitas Gunadarma, Depok, 2010.

[2] Cindy Mutiara Septani, 2013, "Air Pendingin (Cooling Water)", Universitas Brawijaya, Jakarta.

[3] Anggara Yudha Pratama, 2012, "Tugas Utilitas Sistem Air Pendingin (Cololing Water)", Universitas Diponegoro, Semarang.

[4] Faustus Yulius, 2010, "Simulator Otomatisasi Chilled Water Pump Pada Sistem Pendingin Terpusat", Universitas Kristen Maranatha, Bandung.

[5] Author Alkonusa, 2016, "Pengertian Pompa Sentrifugal dan Prinsip Kerjanya".

http://www.alkonusa.com/news/penge rtian-pompa-sentrifugal- danprinsip-kerjanya/.

[6] Dharent, 2016, "Bagian - bagian dari pompa air sentrifugal" https://sekedartulisanweb.wordpress.c om/2016/05/11/bagian-bagian-daripompa-air-sentrifugal/. 
[7] Chandra MDE, 2010, "Rangkaian Sensor Suhu LM35" https://telinks.wordpress.com/2010/04/0 9/rangkaian-sensor-suhu-lm35/ .

[8] Rudy Hermawan, 2014, "Mengatasi sensor arus ACS712 tidak linier : resolved problem", http://jawaplugin.blogspot.co.id/2014/0 8/mengatasi-sensor-arus-acs712tidak.html.

[9] Bintangtio, "Pelajari tentang LCD 2X16 Character", http://k1801.ilearning.me/2015/04/28/pe lajari-tentang-lcd-2x16-character3/\#comments.

[10] Hari Santoso, 2015, “Cara Kerja Sensor Ultrasonik, Rangkaian, \& Aplikasinya",http://www.elangsakti.co m/2015/05/sensorultrasonik.html\#com ment-form. 